To the Editor:

\title{
Cracked skin of feet: an ignored entity in the tropics
}

Vertical cracking of skin at the edge of the soles is seen in many adults of Sri Lanka. However, none of the standard textbooks on dermatology or general medicine describe it as an entity. We were able to find it mentioned in one textbook written by Finnish and African authors [1]. A survey of MEDLINE using key words "cracking of skin", "cracked skin" and "splitting of skin" did not reveal a single article suggestive of this disorder (accessed on 14 October 2003).

The objective of our study was to assess the prevalence, complications and possible aetiological factors of cracked skin of feet.

We conducted two pilot studies in adults ( $>18$ years) from rural areas (Moneragala District) and in an urban population (National Hospital, of Sri Lanka). In the rural study, the samples consisted of consecutive adults attending the general Outpatients' Department (OPD) of Moneragala Base Hospital $(n=42)$ and those selected from a community survey $(n=33)$. In the urban study the prevalence was noted from a consecutive sample of adults attending the general OPD of the National Hospital of Sri Lanka (NHSL) and living in Colombo $(\mathrm{n}=100)$. Exclusion criteria were the presence of serious illness, requiring bed rest or overt skin disease (such as allergy).

A separate case control study of 112 persons was also conducted in the general OPD of NHC, with those observed to have cracked skin of feet being matched for age and sex. Trained pre-intern medical officers collected data and examined participants using structured questionnaires.

The results of the rural study revealed that there were 46 with cracked skin of feet (overall rate of $61.3 \%$, mean age 38.1 years, male:female ratio $=12: 34=2.83$ ) and 29 (38.7\%) without (mean age 20.4 years, male:female ratio $=11: 18=1.63)$. The principal complaints were that of pain $(23,50 \%)$ and bleeding $(7,15.2 \%)$. Pruritus was rare (present only in 2). Moderately or very thick skin in the soles were observed in $43(93.4 \%)$ of those with cracks, whereas only $12(41.4 \%)$ controls had the feature $(\mathrm{p}<0.05)$. Regular footwear was used by six $(13 \%)$ of those with cracks and 11 (37.9\%) controls (not significant).
In the urban study, 58 (58\%) of the subjects (mean age 42.7 years, male:female ratio $=34: 24=1.42$ ) had cracked feet during the past year, while 66 (66\%; male: female ratio $=37: 29=1.27$ ) claimed to have had the problem at some time during their life.

The case controlled study did not show a statistically significant difference in the two groups for use of footwear, positive family history, dry skin (subjective assessment) and body weight. Thick skin was noted in $69(61.6 \%)$ of cases and $15(13.4 \%)$ of controls $(\mathrm{p}<0.05)$. Complications included pain $(\mathrm{n}=56,45.9 \%)$, bleeding $(n=23,18.9 \%)$, pruritus $(n=10,8.2 \%)$ and infection $(\mathrm{n}=6,4.9 \%)$.

This is the first report on cracked feet in the literature to our knowledge. The results indicate a high burden of problems such as pain and bleeding in this disorder. Its possible role in serious complications such as diabetic foot disease needs further investigation.

Thick skin was found to be the only significant factor associated with skin cracking in both rural and urban areas. The single reference suggests that walking barefoot results in thickening of skin, which gets cracked from trauma and drying, but quoted no reference [1]. Investigations are being done to identify other likely mechanisms of the disorder.

\section{Acknowledgements}

We thank Drs Vinod Elangasinghe, Indika Meegahawatta, PL Atapaththu (DMO, Badalkumbura) and health staff from Moneragala District for their assistance, and the Development Studies Institute of the University of Colombo for funding.

\section{Reference}

1. Paananen H. Common Skin Diseases. In: Lankinen L, Bergstrol S, Makela PH, Peltomaa M, eds. Health and Disease in Developing Countries. London: The Macmillan Press Ltd., 1994:271-280.

Saroj Jayasinghe, Associate Professor, Pubudu de Silva, S Mathankumar, KLADT Ranasinghe, MDA Rodrigo and AADCJ Weerathunga, Research Assistants, Department of Clinical Medicine, Faculty of Medicine, Kynsey Road, Colombo 8. Correspondence: SJ, e-mail: <sarojoffice@yahoo.com> (Competing interests: none declared). Received 20 October 2003 and accepted 17 January 2004. 